\title{
TOWARDS A SOCIAL-PRACTICE THEORY OF COMPETITION
}

\author{
PAULA JARZABKOWSKI \\ Cass Business School, City University London \\ 106 Bunhill Row, London, ECY8TZ \\ REBECCA BEDNAREK \\ Birkbeck, University of London
}

\section{INTRODUCTION}

Understanding competition within an industry has been a central focus for the field of strategy (e.g., Porter, 1991). Competition arises "whenever two or more parties strive for something that all cannot obtain" (Stigler, 2008: 1). Much strategy research has focused on the competitive advantage firms can build in order to win over their rivals (Barney, 1991; Porter, 1985). However, we currently lack a practice-theoretical perspective that explains how competition actually unfolds in practice, through the everyday activities of people in firms across an industry. While the strategy-as-practice (s-as-p) literature has developed considerable insights into strategizing practices and their implications for strategy making within organizations (e.g., Balogun \& Johnson, 2004; Kaplan \& Orlikowski, 2013; Mirabeau \& Maguire, 2014), there have been few studies focused specifically on competitive practices and their implications for interorganizational dynamics (for an exception see: Vaara et al., 2004). This dearth of research has led to calls for s-as-p to fill its potential to examine broader inter-organizational phenomena - or wider nexus of practices (Nicolini, 2009; Schatzki, 2002) - such as competition (Jarzabkowski \& Spee, 2009; Seidl \& Whittington, 2014; Vaara \& Whittington, 2012).

We seek to correct this imbalance, through our study of how competition in an industry is enacted in the everyday work practices of multiple dispersed individuals. Adopting a Schatzkian approach (Schatzki, 2002, 2005), we study competition by following a nexus of practices, defined as recognizable patterns of doings and sayings, across multiple actors and sites in an industry (Seidl and Whittington, 2014). We focus on the practices associated with competition between existing players within an industry (Porter, 1991) and our practice theory perspective draws on but goes beyond the existing strategy literature into competitive dynamics (Chen \& Miller, 2012; 2014).

Our findings identify various activities associated with two forms of competitive practices: positioning and leveraging. We develop these into a dynamic model of the process through which multiple firms compete across a number of deals in varied ways; which we are able to explain according to their different beliefs in diversification and their immediate fluctuations in capital availability. Our findings are drawn together in a conceptual framework that provides insight into competition as a dynamically unfolding process that is negotiated and renegotiated continuously within each trade by each competitor in an industry. At the same time, we shed light on notions of competition within consensus-based industries. Our findings and framework extend the strategy-as-practice literature, which has not, as yet, looked at the practice of competitive dynamics within an industry as it unfolds in the everyday micro-activities of multiple situated actors (Jarzabkowski \& Seidl, 2008; Rouleau, 2005). In doing so, we begin to address the call for strategy-as-practice research to address "larger questions" about strategizing and its implications (Jarzabkowski \& Spee, 2009; Seidl \& Whittington, 2014; Vaara \& Whittington, 2012; Whittington et al., 2003). 


\section{A GLOBAL ETHNOGRAPHY INTO COMPETITION IN THE REINSURANCE INDUSTRY}

Reinsurance is a financial industry which provides insurance to insurance firms through the provision of capital to cover (potential) large scale losses. We conducted a three year global ethnography which allowed us to follow trading reinsurance deals across multiple sites (Marcus, 1995). Certain characteristics of how reinsurers compete are particularly interesting. Namely, all reinsurers providing capital to any deal do so at the same "consensus" price; regardless of any differentiation between them in terms of security or strategic position, none of up to 60 reinsurers on the deal gets a higher price for their capital. This consensus terminology should not obscure the intense competition between reinsurers. While they collectively establish the consensus price, they do so through a competitive process of individual quoting, in which firms seek to position themselves favorably relative to their competitors without knowing how those competitors are themselves positioning their quotes (Dutta et al., 2003). As we sat alongside reinsurance managers, and interviewed them and their CEOs, we saw their strongly competitive behavior, despite this consensus market for trading capital. Our interest in understanding the practicetheoretical nuances of competing within such complex competitive dynamics was sparked, leading to this paper. We engaged with 22 reinsurance firms and three reinsurance brokerage firms, drawing from multiple data sources, including 935 observations and 382 interviews. We focused our observations on the renewal period, the lead up to the key date were multiple reinsurance deals come up for annual renewal.

\section{FINDINGS}

\section{Positioning and Leveraging Practices during Quoting and Capital Allocation}

Competition unfolds at two stages as reinsurers compete to shape the price at the point of quoting a deal and for share at the point of capital allocation. We cluster the various activities as positioning (competitor-focused actions firms take to position themselves relative to their competitors) and leveraging (client-focused actions by firms to leverage any advantage in their existing position with a client) practices.

Competing whilst shaping the price. Competing at the point of quoting can be understood as a struggle over competing for the deals you find most attractive while also seeking to influence the price of deals upwards. First, during the price setting (or quoting phase) firms compete for a share of deals that they find attractive. Those who quote are typically seen by clients (and brokers) as serious competitors and rewarded with larger shares. The main shares on a deal will go to reinsurers who have provided quotes within the ballpark of the eventual consensus price: "you quote, usually you will get a share if you are still within the market [range] and not too far off" (Interview). If or when reinsurers' quotes are too much of an outlier, they are often dismissed, losing their ability to compete for a share. Second, reinsurers are also competing for influence, specifically to be one of the firms that set the eventual, consensus, price of those deals. While only one quote will be chosen as the consensus price offered to the entire market for a deal, selecting that price will be influenced by the range of higher and lower quotes received. Hence, even where a quote is not selected, depending where it falls within the range of quotes received, it influences the eventual price. Reinsurers ideally would like to push the price higher in order to get the best price possible for capital. However, any one reinsurer cannot set the price alone but instead does so relative to those they are competing against. 
An example of positioning practices are managers seeking to position their quotes relative to their competitors' actions to gain a share of the deal, while also simultaneously competing to influence the price. Because quoting is a competitive process, reinsurers do not know what others are quoting when they pitch their own prices. Consequently, prior to the act of quoting, positioning practices revolve around collecting and discussing information to help individual actors determine how their competitors are also positioning quotes. Reinsurers frequently adjust their quotes in accordance with their assessments of the (partial) information they have about competitors and the market so as to be within the ballpark. In positioning their actual quoted price, reinsurers, generally, want to help increase the price of any deal. However see how the positioning practices regarding the quotation unfold in various ways based on the intensity with which the reinsurer is competing on to either influence the price, for share or both. For example, if they consider a deal very attractive, reinsurers can make a competitive decision to quote "lower", being more interested in competing for a share of the deal rather than to influence the price upwards.

Leveraging practices involve seeking to leverage an existing position with a client to influence the price or gain a share of a deal. In particular, reinsurers reference their long-term relationship, their elevated expertise in evaluating particular deals, and their high quality security as a way to increase their influence on the price of a particular deal whilst maintaining a share. For example, as those firms offering a bigger share are typically more important to clients, this allows firms willing to offer a large share to stand out from a reinsurer offering a small share. A high quotation from a reinsurer offering $20 \%$ share is likely to help push the price of that deal upwards, whereas a quotation from a reinsurer offering $2.5 \%$ share has less influence.

Competing while being allocated share. Actively competing for share becomes the sole focus once the consensus price is established. As this point, the price will not change but rather competition shifts to focus solely on how much share of that deal the reinsurer will get: "We're all going to get the same [price] at the end of the day. The difference is how much we get out of that deal" (Interview). In particular, as reinsurers compete to retain or increase their desired share on the deals that are most attractive to them, this can often mean taking a share from others on the deal. We again were able to categorize the intensity of competition: those firms competing hard for a share, those firms competing less hard (for instance, perhaps for a small share), and those firms who walked away from the deal as the price was not right.

The majority of activities upon receiving the consensus price focusing on leveraging: using their current position with a client to win the share of that deal they want. This involves various negotiating tactics during which reinsurers leverage three things: their relationship longevity (and in-depth knowledge this implies), the amount of capital they can offer, and other deals of that client for which they might offer cover. As they compete for share, reinsurers remained attuned to the moves of their competitors in order to make the most of any opportunities through ongoing positioning practices. Reinsurers collected and acted upon information about the movements of their competitors. They used this to pursue opportunities where increased share of deals might be possible. Further, those reinsurers who had not been competing too intensely throughout the process can still look out for any opportunities to come on as a "following market" on deals they consider attractive enough and where clients are looking for additional capital. This entails much conversation and interaction with brokers and clients to ensure they remain aware of any such opportunities. These newcomers are termed following markets, as they only competed for share at the point of capital allocation following the consensus price made by others. 


\section{Variation and Dynamism in Competitive Intensity amongst Firms and Across Deals}

In following the nexus of practices spatially (across players and deals) and temporally through the renewal period (Schatzki, 2002; Seidl \& Whittington, 2014), our framework shows how these competitive practices (positioning and leveraging) unfold dynamically across multiple deals and between multiple competitors. First, competitors each have varying appetite for any particular deal at the outset. Second, the intensity for which any reinsurer competes for a particular deal can vary throughout the renewal period. We explain these differences according to different enactments of diversification in selecting which deals to compete upon and fluctuations in each firm's particular capital availability according to the moment-by-moment decisions they make during the renewal period. That is, whether actors compete more or less hard for a deal at the quoting stage and whether this intensity of competition shifts as they come to the capital allocation stage is shaped by the way they enact their beliefs in diversification and by the fluctuations in their capital availability arising from the unfolding decisions they are making throughout the renewal period.

Diversification. On any deal some firms will be competing fiercely while others do not. That is, there is much variation in competitive intensity between reinsurers for any particular deals. This variation can be explained by different enactments of diversification by the various reinsurance firms. Reinsurance firms develop diversified portfolios to reduce the likelihood that any single event, for example a Florida hurricane, will threaten the survival of the firm (Cummins \& Trainar, 2009; Markowitz, 1952). They might decide to be widely diversified across multiple international territories and types of risks, or to diversify more modestly within only some territories and risks. Consequently, each reinsurer assesses a deal (and its price) relative to their own specific portfolio, which could make the deal more or less attractive form a diversification perspective depending on the transactions they have already made.

Reinsurance firms vary in their belief in diversification. There is no magical mathematical formula that determines what level of diversification is required or optimal. While any reinsurer diversifies, each has a vastly different perception of the degree (and type) of diversification that is desirable. For example, some reinsurers, compete only in a small subset of market that they consider most profitable or understandable. As one underwriting manager explained "diversification is good - yes; but only to a certain extent" (fieldnote). By contrast, other firms enact a broader definition of diversification, believing that the more they spread the risks the better. As a underwriting manager from another firm explains: "when you have an across-the-board approach, at least you have a more robust portfolio. If you have a loss you have more diversity so it doesn't impact as much of your portfolio" (Interview). This influences what deals any particular reinsurer will compete for.

Capital availability. Competition is also enacted dynamically throughout the renewal period, as different actors deploy their available capital around opportunities and wins and losses that unfold in their moment-by-moment dealings with the market. This fluctuation in competitive intensity is explained, primarily, by the fact that competition is an enactment of capital availability, which fluctuates as transactions are made. Reinsurers require capital to provide cover for, and thus transact on, any reinsurance deal. Therefore, the amount of spare capital reinsurers have available determines how fiercely they will compete for a deal. This again helps explain the variation we observed. For example, "Florida Hurricane" or "Romanian Earthquake" will each have a certain amount of capital available to them to avoid over-exposure to any one type of risk. Consequently, if an underwriting manager has nearly run out of Florida capital, a 
particularly good price is needed to continue to compete for another deal in this territory. Conversely, a firm wants to ensure that all of its capital is working; meaning they might compete more intensely if they have spare capital.

This capital availability fluctuates within any particular renewal period, meaning reinsurance dynamically adjust how they compete. Capital availability evolves as firms "used up" that resource during each transaction they made, meaning how fiercely a firm competes on any one deal evolves dynamically in relation to the how they compete on other deals. Furthermore, while reinsurers can put aside capital for a particular client they cannot control whether their capital will be allocated as expected. Namely, their actions are partly dependent on the moves of their competitors and the decisions making of the client.

Summary. The everyday practices of actors within their firms' vis-à-vis specific deals enact competition on a deal-by-deal basis in a way that, collectively across multiple across and multiple deals, constitutes the competitive dynamics within which each individual competitor acts. When we follow the nexus of these competitive practices across multiple actors and deals and over time (Schatzki, 2002) we can see that this competition unfolds as a dynamic process, shaped by and shaping variation in how different firms compete on any particular deal. Practical, everyday enactments of diversification and fluctuating capital availability are critical explanators of this variation in the competitive intensity of individual reinsurers for particular deals and how this fluctuates over the renewal period.

\section{TOWARDS A PRACTICE-THEORETICAL FRAMEWORK OF COMPETITION}

This paper set out to provide a practice theoretical approach to competition. Our findings illustrated how competition unfolds within the positioning and leveraging practices of individual actors. We followed these practices as they unfolded as a nexus across multiple actors and multiple deals over time. This process framework builds from the two layers of findings that highlighted, respectively, the positioning and leveraging practices that enact competition and how this unfolds dynamically across multiple actors and deals.

A number of contributions stem from this framework. First, competition is depicted as something actors $d o$ as they engage on individual deals. We provide a rare study within the s-asp literature (Jarzabkowski \& Spee, 2009; Vaara \& Whittington, 2012) that highlights everyday strategizing actions as critical to competition. In particular, we depict the positioning and leveraging practices which unfold as part of the everyday work of actors and through which industry competition is enacted. Rather than building our notion of competition through macroconcepts of "industry" or "groups", as per the traditional strategy literature (Bogner \& Barr, 2000; Porac et al., 1989; Porter, 1998), we focus on competition as constituted within the actions of particular actors on individual deals. This focus on everyday work as it is distributed across multiple across the industry, not necessarily directly acting or interacting with each other, differs from a focus on explicit action/reaction dynamics focused on larger-scale actions within specific competitive dyads, as in the competitive dynamics literature (Chen \& Miller, 2012; Chen \& Miller, 2014). Rather than focus on explicit interactions between clearly defined competitors, we describe competition as unfolding within the everyday actions of actors as they transact on deals, sensitive to the moves of, but not directly interacting with, their competitors.

By depicting competition as unfolding on a deal-by-deal basis we provide a distinct picture of the competitive "positions" of the various actors involved. Monolithic, or static, labels of competitors such as "leaders" and "challenges" (Bogner, Thomas, \& McGee, 1996; Ferrier et 
al., 1999) thus emerged as less relevant. A large firm can be a central competitor on some deals and a peripheral player on other deals and a smaller firm can be extremely influential on any particular deal. Furthermore, this more fine-grained view depicts how firms compete differently on different deals. This means our understanding of competition moves beyond notions of headto-head "battle" or a zero-sum game (Chen \& Miller, 2014); rather, a more nuanced picture of the relationship between competitors emerged. A view of competition as constantly enacted and reenacted - and indeed renegotiated - on a deal-by-deal basis thus advances our understanding of the multi-faceted relationships and dynamics between competitors.

Second, a practice approach to strategizing enables deeper understanding of competition as a process. That is, how these practices unfold both over time and also through in-the-moment actions (Chia \& MacKay, 2007; Langley, 2007). In our case, competition at the point of allocating share to a deal differs and evolves from competition at the point of quoting. These different actions are interconnected as a pattern of activity that evolves dynamically around competition for each single deal. Competition is thus shown to be constantly "reproduced, adapted and defined" through the practical work of actors as they go about their daily strategy work (Chia \& Holt, 2006; Langley, 2007; Tsoukas \& Chia, 2002). As we developed our understanding of competition as a process we followed the nexus of competitive practices temporally, spanning multiple deals and players, and comprising a collective industry practice (Schatzki, 2002; Seidl \& Whittington, 2014). Competition evolves at the nexus of practices of multiple actors across multiple deals, including as actors shift their practice on one deal in relation to their own and their competitors' practice on another deal. In summary, a practice perspective has allowed us to develop a nuanced picture of competition as a dynamic process that spans across and shifts with the moves of multiple actors on multiple deals.

Third, we provide a practice-theoretical approach to understanding not only competition but also how strategically relevant dynamics unfold amongst organizations. In doing so, we contribute to and extend existing, rather sparse understandings in the s-as-p literature concerning the discursive formation of inter-organizational categories of competition, such as alliances (e.g. Vaara et al, 2004). Following the nexus of leveraging and positioning practices over time and across multiple actors and deals provided an example of how an inter-organizational dynamic such as competition is enacted within the everyday practices of actors. In so doing we directly address a call in the s-as-p literature for more studies that span from the micro situated work of individuals to broader inter-organizational phenomena (Jarzabkowski \& Spee, 2009; Vaara \& Whittington, 2012). In particular, we offer strategy scholars a specific practice lens through which to address such questions (Seidl \& Whittington, 2014); namely, a Schatzkian one (Schatzki, 2002). We show how the everyday practice of actors $i s$ the actual competition that they also collectively experience: so-called larger phenomena constituted as a nexus of practices across players and sites (Marcus, 1995).

\section{REFERENCES AVAILABLE FROM THE AUTHOR}

